\title{
Mast cell-mediated and associated disorders in pregnancy: a risky game with an uncertain outcome?
}

\section{Katja Woidacki ${ }^{1}{ }^{*}$, Ana Claudia Zenclussen ${ }^{1}$ and Frank Siebenhaar ${ }^{2}$.}

1 Experimental Obstetrics and Gynecology, Medical Faculty, Otto-von-Guericke University, Magdeburg, Germany

2 Department of Dermatology and Allergy, Allergie-Centrum-Charité, Charité-Universitätsmedizin Berlin, Berlin, Germany

\section{Edited by:}

Sinuhe Hahn, University Clinics Basel, Switzerland

Reviewed by:

Masato Kubo, Tokyo University of Science, Japan

Grzegorz Szewczyk, Warsaw Medical University, Poland

\section{*Correspondence:}

Katja Woidacki, Experimental

Obstetrics and Gynecology, Medical

Faculty, Otto-von-Guericke University Magdeburg,

Gerhart-Hauptmann-Street 35,

Magdeburg 39108, Germany

e-mail: katja.woidacki@med.ovgu.de,

Frank Siebenhaar, Department of

Dermatology and Allergy,

Allergie-Centrum-Charité,

Charité-Universitätsmedizin Berlin,

Charitéplatz 1, 10117 Berlin, Germany

e-mail:frank.siebenhaar@charite.de
During pregnancy, the maternal organism is under the influence of tremendous endocrine as well as immunological changes as an adaptation to the implanted and developing fetus. In most cases, the maternal adaptations to pregnancy ensure both, the protection against harmful pathogens and the tolerance toward the growing semi-allogeneic fetus. However, under certain circumstances the unique hormonal milieu during pregnancy is causative of a shift into an unfavorable direction. Of particular importance are cellular disorders previous to pregnancy that involve cell types known for their susceptibility to hormones. One interesting cell type is the mast cell (MC), one of the key figures in allergic disorders. While physiological numbers of MCs were shown to positively influence pregnancy outcome, at least in mouse models, uncontrolled augmentations in quantity, and/or activation can lead to pregnancy complications. Women that have the desire of getting pregnant and been diagnosed with $\mathrm{MC}$ mediated disorders such as urticaria and mastocytosis or chronic inflammatory diseases in which MCs are involved, including atopic dermatitis, asthma, or psoriasis, may benefit from specialized medical assistance to ensure a positive pregnancy outcome. In the present review, we address the course of pregnancy in women affected by $\mathrm{MC}$ mediated or associated disorders.

Keywords: mast cells, pregnancy, urticaria, PUPPP, mastocytosis, atopic dermatitis, asthma, psoriasis

\section{INTRODUCTION}

Pregnancy represents a unique challenge for the maternal organism. Tremendous endocrine and immunological modifications that occur as an adaptation to the implanted embryo ensure a successful pregnancy outcome. These necessary changes in the hormonal state and the shift toward anti-inflammation can, however, cause a dysregulations in the number and behavior of mast cells (MCs). MCs have been shown to exhibit beneficial function in pregnancy by contributing to implantation, placentation and fetal growth through their release of the glycan-binding protein galectin- 1 and, thus, are critically implied in the fetomaternal interface (1). In addition, MCs influence pregnancy by modulating non-immunological responses by contributing to tissue remodeling, angiogenesis, and spiral artery modifications (1). In later pregnancy phases, however, MCs display rather detrimental functions as an excessive release of MC-mediators in parturition are associated with pre-term delivery. MC activation is modulated by hormonal endocrine signals that could lead to altered functional behavior of MCs in various innate and adaptive immune responses (1). In particular, pre-existing MC mediated and associated disorders may affect disease progression and the disease itself may influence pregnancy outcome. Sex hormones are considered to influence the clinical course and severity of chronic allergic and inflammatory diseases, including atopic dermatitis (AD), asthma, and psoriasis (2-5). In fact, estrogen and progesterone have been reported to modulate tissue homeostasis and immunological responses in various conditions.
Here, we review the existent literature on the clinical implications of MC associated disorders in pregnancy, focusing on directly MC mediated disease such as urticaria and mastocytosis, but also summarize the disease impact on pregnancy of common inflammatory disorders in which MC have been reported to critically contribute to the pathogenesis. Hereby, we offer an overview of how disease-specific modifications in MC function and activation could determine the fate of pregnancy.

\section{ROLE OF MAST CELLS AND MAST CELL MEDIATORS IN PREGNANCY}

Mast cells reside in the endometrial tissue and uterine MCs exhibit signs of activation during premenstrual stages (6). MCs granules consist of a large array of mediators, including histamine, prostaglandins, leukotrienes, several cytokines, and proteases (7). The release of MC protease such as tryptase has been reported to stimulate the production of matrix metalloproteinases (MMPs) that are involved in the degradation of extracellular matrix components. Increase protease expression is detected during menstruation (8). Histamine, which is produced and released by MCs, has been reported to be involved in blastocyst implantation and placenta development by contributing to and promoting trophoblast invasion, growth, and the expression of adhesion (9, 10) molecules. During pregnancy, the number of MCs increase in the myometrium and equal ratio of tryptase and chymase $\left(\mathrm{MC}_{\mathrm{TC}}\right)$ positive $\mathrm{MCs}$ shift toward a tryptase-only $\left(\mathrm{MC}_{\mathrm{T}}\right)$ phenotype (11). Here, histamine, prostaglandins and MC proteases have 
been shown to contribute and modulate myometrical contractility $(12,13)$. MC proteases may also be involved in post-partum uterine tissue remodeling (14). Given these facts, it is reasonable to suggest that MCs influence pregnancy outcome under physiological conditions and even more relevant when their activation status is modulated by disease. The prevalence of MC mediated and associated disorders, including allergic and non-allergic diseases, is increasing. Severe allergic reaction, i.e., anaphylaxis during pregnancy can indeed result in pre-term labor whereas adequate treatment, including antihistamines and corticosteroids, reportedly inhibited uterine contractions (15). This evidence points toward the importance of disease management of MC-related disorders during pregnancy. Although, the use of systemic treatments should be limited or even generally avoided in pregnancy - especially in the first trimester, pregnant women require best possible treatment. But how to provide best possible treatment by calculated risk profile? The use of second-generation antihistamines (sgAH) for example is widely used for the treatment of allergic disease. In pregnancy, it is recommended to limit the use of sgAH to loratadine (16), and possibly desloratadine, because of best available evidence. Nowadays, several AH are OTC (over-thecounter) products in many countries and it can be assumed that these drugs are frequently used by pregnant women - at least before they knew to be pregnant. However, up-dosing of sgAH as it is recommended in the management of chronic urticaria must be carefully suggested in pregnancy since safety studies have not been performed (17).

\section{URTICARIA IN PREGNANCY}

Urticaria is a very common dermatological condition in which an increased activation of MCs and the subsequent release of MC-mediators, mainly histamine among others, lead to the development of wheal-and-flare responses accompanied by an intense pruritus on the skin (18). Urticaria is divided into acute (less than 6 weeks) and chronic (more than 6 weeks) forms as well as into inducible and spontaneous occurring subtypes (17). Urticaria may develop during pregnancy even though it is not considered as a specific pregnancy dermatosis. MCs have also been reported to contribute to the pathogenesis of pregnancy-related dermatoses associated with pruritus that are restricted to pregnancy, e.g., pruritic urticarial papules and plaques of pregnancy (PUPPP). Urticaria can either develop during pregnancy or the symptoms of a pre-existing chronic spontaneous urticaria (CSU) may change in terms of disease activity and severity. Influence of sex hormones on MC functions and the pathogenesis of CSU have long been considered (19). CSU is approximately twice more frequent in women than in men and the disease activity of CSU may be associated or triggered by fluctuation of sex hormone levels, including menstrual cycle, pregnancy, menopause, and hormonal therapies (19). CSU may worsen with pregnancy in some patients but also improve in others (20). Hypersensitivity to sex hormones and their modulating actions on MCs have been implicated in the pathogenesis of CSU and altered hormone serum levels have been described in subgroups of CSU patients (21). Thus, such fluctuations in the hormonal milieu have been suspected to either improve, maintain, or aggravate urticarial lesions during pregnancy (19). PUPPP and other pregnancy-related dermatoses associated with pruritus should be considered as differential diagnosis if wheals and itch newly occur in pregnancy, especially during the third trimester (22). In addition, special treatment considerations should be applied to pregnant and lactating women $(17,23)$.

\section{PRURITIC URTICARIAL PAPULES AND PLAQUES OF PREGNANCY}

Pruritic Urticarial Papules and Plaques of Pregnancy or polymorphic eruption of pregnancy (PEP) is the most common pregnancyrelated skin disorder with an incidence of about 1:160-1:200 (24). This disease appears and exists exclusively in pregnant patients. Besides the pruritic urticarial papules and plaques, which represent the key symptoms of PUPPP, more than one-half of the patients later develop polymorphous features including erythema, vesicles as well as targetoid and eczematous lesions (25). Characteristically, the eruptions begin on the abdomen, particularly, within or adjacent to striae cutis distensae and occur predominantly in the third trimester in about $83 \%$ of the patients (25-27). It is suggested that multiple gestations and an excessive maternal weight gain is associated with the occurrence of PUPPP $(25,28)$. The fetal weight and sex does not seem to be related to the onset of PUPPP (25). Cortisol serum levels have been found to be significantly reduced in PUPPP patients whereas estradiol concentrations were comparable with unaffected women (27). It is tempting to speculate that MCs are involved in the onset of PUPPP although no studies are existing showing a direct link between MCs and this disease. It is suggested that the activation of the skin immune system characterized by increased numbers of dentritic cells and activated T cells in lesional skin contribute to the pathology of PUPPP (29). Skin infiltrates of macrophages $(30)$ and eosinophils $(25,27)$ have been described in affected tissue. Although, a direct implication of MCs has, as of yet, not been reported in PUPPP there are several lines of evidence that clearly suggest a role for MCs. First, as in urticaria, antihistamines are the first line option in the treatment of PUPPP and are effective in most patients. MCs are considered as the main source of histamine in the skin (31). Second, even though PUPPP and urticaria are different diseases there are several similarities in terms of the clinical symptoms including pruritic erythema and urticarial lesions. Third, autologous whole blood injections have been reported as an effective treatment option in PUPPP as it is in auto-reactive $\operatorname{CSU}(32,33)$. Therefore, even if still speculative it is not unlikely that the release of MC-mediators critically contribute to the pathogenesis of PUPPP.

\section{MASTOCYTOSIS AND PREGNANCY}

Mastocytosis represents a group of related disorders, each characterized by a pathological accumulation of MCs in one or more organs ranging from indolent to very rare aggressive forms (34). Mastocytosis is classified as a rare disease with an estimated prevalence of around 1 per 10,000 and dividing cutaneous from systemic forms (35). About $80 \%$ of mastocytosis patients carry an Asp816Val mutation in the catalytic domain of the c-Kit receptor downstream tyrosine kinase in peripheral blood mononuclear cells (36). This point mutation mediates an increased proliferative rate of MCs (37). An addition explanation for the increased numbers of MCs in tissues from mastocytosis patients might be the enhanced chemotaxis of CD117 positive cells. It is speculated 
that MC progenitor cells bearing the D816V mutation preferentially migrate to SCF produced by stroma cells, endothelial cells, fibroblasts, and keratinocytes in the skin (38). It could be shown that MCs present in the lesions express SCF suggesting a potential autocrine or paracrine growth and differentiation loop for MCs and lymphoid progenitors $(39,40)$. Differentiation of the mutant progenitor cells into mature MCs occurs locally based on the specific microenvironment. Thus, enhanced MC migration combined with aberrant proliferation contribute to the extensive MC hyperplasia observed in affected tissues (38). Beside the elevated serum tryptase levels in mastocytosis patients (41), the coexpression of CD25 antigen in bone marrow MCs turned out as diagnostic marker in mastocytosis $(42,43)$. In bone marrow biopsies from mastocytosis patients, MCs are surrounded by lymphoid aggregates, which consist of a mixture of B and T cells $(39,44)$. Similar to MCs, these B and T cells carry the D816V mutation (44).

Between $20 \%$ and one third of pregnant women with mastocytosis reported a worsening of the diseased-related symptoms $(45,46)$. Around $30 \%$ experienced a clinical improvement during the first trimester. In the other half of the affected population, MC-mediator related symptoms remained unchanged (46). Interestingly, worsening of symptoms was observed during the first or third trimester (46) when Th1-mediated pro-inflammatory conditions dominate (47-49). Although, women diagnosed with mastocytosis are often required to continue the intake of medications including antihistamines during pregnancy the doses are often decreased because of fetal safety concerns (45). The reduction in medication as well as an irregular medication intake could contribute to worsening of mastocytosis symptoms as well. Undiagnosed and not appropriately treated mastocytosis can be associated with severe pregnancy complications including fetal demise (50).

Parturients suffering from mastocytosis that do not undergo a natural birth represent a particular challenge for anesthesiologists. During the process of labor, life-threatening complications may occur, particularly due to the risk of anaphylactoid reactions triggered by anesthesia. Medications such as glucocorticoids, antihistamines, and epinephrine should be available during the critical phases of labor and the early post-partum period (51).

In general, studies describing the impact of mastocytosis in pregnancy and vice versa are limited. Thus, one can only speculate that the unique pregnancy-associated micromilieu composed of hormones and myriads of mediators contribute to variations in the disease pattern.

\section{ATOPIC DERMATITIS IN PREGNANCY}

Atopic dermatitis is a complex chronic inflammatory condition in which MCs have been shown to contribute critically to the pathogenesis and the induction of inflammation and pruritus. MC number and degranulation is increased in atopic lesions (52). It is suggested that the invasion and degranulation of MCs within peripheral nerve bundles may provoke and aggravate itchiness of AD (53). MC-derived mediators might participate in epidermal hyperplasia seen in lichenified lesions in $\mathrm{AD}$ (54).

Atopic dermatitis is one of the most prevalent dermatoses during pregnancy $(55,56)$ and pregnancy may alter the clinical course and severity of AD. More than half of pregnant women with pre-existing $\mathrm{AD}$ were reported to experience worsening of their disease during the second or third trimester $(57,58)$ when a constant Th2 response is maintained. During pregnancy an immunologic homeostasis tolerating the fetus is of crucial importance. To prevent fetal rejection, maternal $\mathrm{T}$ cell mediated immunity is modulated. AD is widely accepted as a Th2-dominated disorder. Therefore, alteration in the Th1/Th2 balance is suggested to promote AD severity, which is often observed in pregnancy (59). MCs found in $\mathrm{AD}$ lesions are a major source of IL- 4 and store higher amounts of IL-4 compared to MCs in normal skin (60). Exogenous IL-4 has been shown to be important for the differentiation of T helper cells into Th2 cells (61). Thus, one can speculate that MCs participate in the Th1/Th2 switch and therefore disease severity (Figure 1). Moreover, IL-4 induces the proliferation of fibroblasts (62) and atopic fibroblasts contribute to the pathogenesis of $\mathrm{AD}$ by initiating strong proliferation and differentiation defects in keratinocytes (63).

Variations in sex hormone concentrations seem to be related with the severity of $\mathrm{AD}$ that is supported by the finding that ca. one third of women reported a premenstrual deterioration in the symptoms $(57,58)$. Sex hormones may also directly influence AD symptoms by their effects on MCs, mediator release, and IgE production (64) (Figure 1). No reported evidence point toward direct influence of $\mathrm{AD}$ on infertility or increased rates of miscarriage, birth defects, or prematurity (65). However, AD patients that are more prone to suffer from bacterial or viral super-infection may be at a higher risk for birth complications including premature delivery, intrauterine growth restriction, or miscarriage (66). The application of large doses of triamcinolone acetonide for treatment of $\mathrm{AD}$ should be avoided as it was related with intra uterine growth retardations (67). Therefore, specific considerations about the treatment strategies in AD during pregnancy will apply to control the impact of $\mathrm{AD}$ progression and complications that may occur on pregnancy.

\section{ASTHMA AND PREGNANCY}

In 2004, the number of people affected by asthma worldwide was estimated as 300 million with a further increase up to 400 million asthmatics by 2025 . The rate of asthma increases as communities adopt western lifestyles and become urbanized (68). It is assumed that environmental estrogens participate in the development of asthma as they induce MC degranulation via the estrogen receptor- $\alpha$. These pollutants show estrogen-like activities, tend to degrade slowly, have a long biological half-life, and bioaccumulate and bioconcentrate in the food chain (69).

Asthma is characterized by recurrent episodes of airway obstruction, which reverse either spontaneously or after use of medication. It is usually associated with bronchial hyperresponsiveness and evidence of chronic airway inflammation (70). The earliest text where the term "asthma" was mentioned in a medical context is in the Corpus Hippocraticum. Several centuries later during the second half of the first century A.D. Aretaeus the Cappadocian was the first one who dealt with asthma as an autonomous clinical disease and not as a symptom (71). One characteristic of asthma is the exaggerated narrowing of the airways that is caused by contraction and shortening of airway smooth muscle (ASM) cells. However, the cause of the induced 


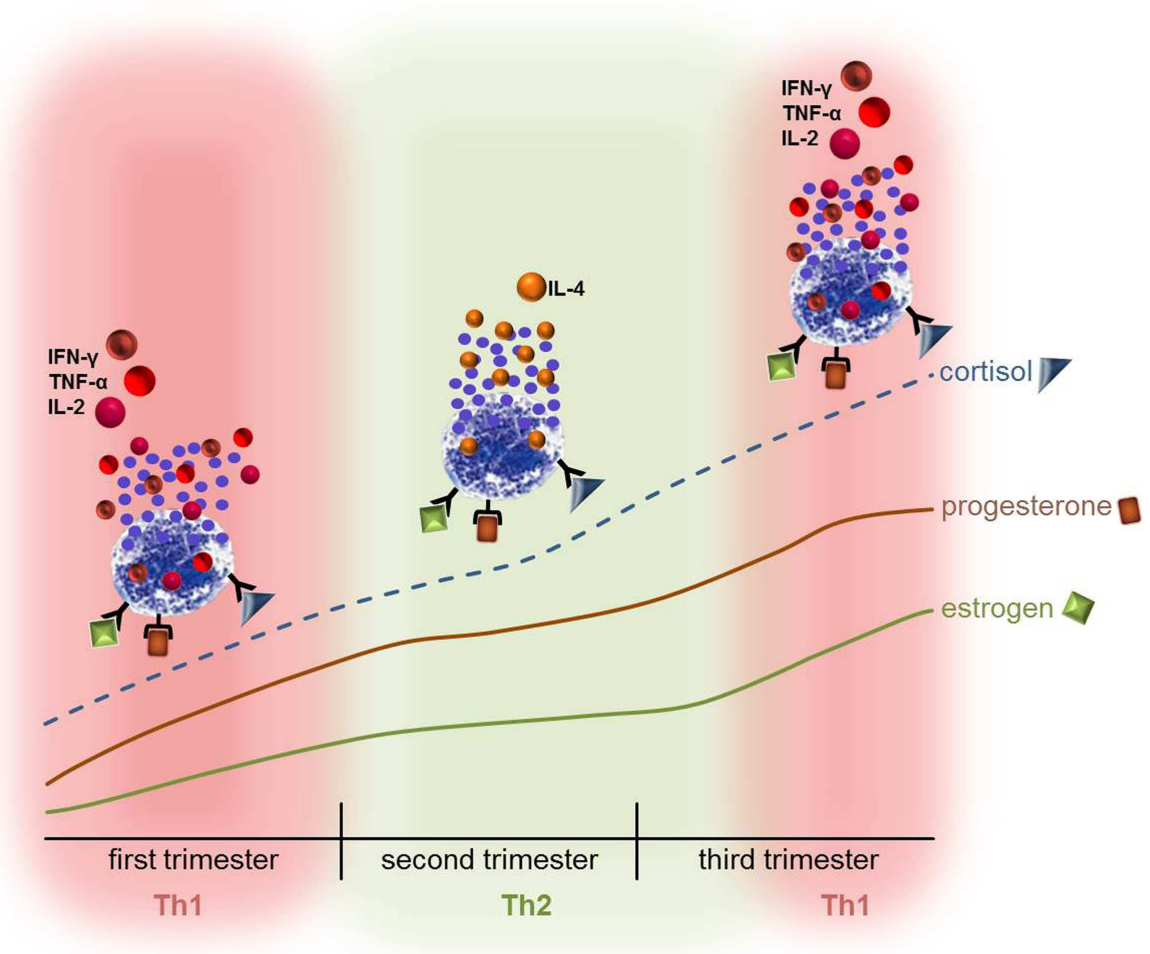

FIGURE 1 |The hormonal stimulation of mast cells during pregnancy might contribute to the Th1/Th2 switch that takes place in pregnancy. The ever-going increase in estrogen, progesterone, and cortisol could directly influence the activation status and behavior of MCs and lead to the release of either pro- or anti-inflammatory mediators thus contributing to the Th1 or Th2-based micromilieu. Hence, disorders that are mediated by MCs or in which MCs are involved may turn into an unfavorable direction. It is however also possible that the symptoms ameliorate due to the hormone-modulated behavior of MCs. displacement behavior of the ASM is still a matter of discussion. It is proposed that following processes could contribute to the SMC response: (1) changes in ASM structure and/or behavior; (2) structural and/or mechanical alterations in the non-contractile structures of the airway wall, and (3) variations in the relationship of the airway wall to the surrounding lung parenchyma (72). The airway remodeling observed during the course of asthma includes the increase in the smooth muscle cells surrounding the airway wall, a deposition of extracellular matrix components under the epithelial basement membrane that causes a thickened appearance, a breach in the integrity of the airway epithelium and an increase of mucus-producing goblet cells in the epithelium or submucosal glands (73).

Various immune cell types including macrophages, eosinophils, and MCs participate in the process of airway remodeling; accordingly they were found in high numbers in bronchoalveolar lavage and in bronchial biopsies from asthmatic patients (74). Asthma is i.a. characterized by an infiltration of MCs in the bronchial epithelium (75), mucous glands, and smooth muscle $(76,77)$. It is hypothesized that the ASM itself induce the migration of MCs and their progenitors via the release of the chemoattractants CXCL9, CXCL10, CXCL11, stem cell factor (SCF), and transforming growth factor (TGF)- $\beta$ (78-80). ASM would also induce MC proliferation and survival (81). Once resident in the ASM bundle,
MCs adhere to it via cell adhesion molecule 1 (CADM1) (82). The release of MC-mediators such as histamine, prostaglandin $\mathrm{D}_{2}$, and leukotriene $\mathrm{C}_{4}$ upon activation induces typical asthmatic symptoms including bronchoconstriction, mucus secretion, and mucosal edema (80). It is often assumed that the activation of MC during asthma is allergen-dependent via the high affinity $\operatorname{IgE}$ receptor FceRI $\alpha$. Mucosal MCs present in bronchial tissue from asthmatic patients exhibit features of chronic activation (83).

About $1 \%$ of pregnant women are diagnosed with active asthma (84). The inflammatory response induced in asthmatic airways contributes to the pathophysiology of this disease (85). This in turn could interfere with the necessary variations in the cytokine milieu mandatory for pregnancy to occur and be maintained. The first trimester and also the early phases of the second trimester of pregnancy require a strong inflammatory response in order to ensure uterine tissue remodeling and clearance of cellular debris (47-49). During the course of pregnancy, the concentrations of the steroid hormones estradiol $\left(\mathrm{E}_{2}\right)$ and progesterone $\left(\mathrm{P}_{4}\right)$ raise more than fivefold followed by a further fivefold increase by term (86). The immunological shift toward Th1 responses at the beginning of pregnancy is mediated by enhancing pro-inflammatory cytokine production by monocytes and macrophages (87), dendritic cells (88) as well as MCs (89) (Figure 1). The ever-going increase in estrogen, progesterone, and cortisol concentrations at 
midpregnancy supports a shift toward Th2 responses, which are necessary for maintaining pregnancy (90). As asthma is a classical Th2-driven disease its course may be negatively influenced by the establishment of an anti-inflammatory milieu as it is observed in the second and early third trimester (91). Indeed, during pregnancy asthma worsens in $35 \%$ of the women with an increase in asthma symptoms starting at the third trimester (92) when a constant Th2 milieu was established. MCs express the receptors for $\mathrm{E}_{2}$ and $\mathrm{P}_{4}(93,94)$ and degranulate upon treatment with theses hormones (94). Based on these findings, one might speculate that the rising levels of estrogens and progesterone during pregnancy stimulate MCs to degranulate (Figure 1) whereby they could negatively influence the course of asthma. This could be an explanation of why one third of women present a worsening of asthma symptoms at midpregnancy (92). However, $28 \%$ of the women experienced an improvement of asthma symptoms and further 33\% showed no changes (92). Women who reported changes in their asthmatic symptoms during pregnancy reverted post-partum toward their pre-pregnancy asthma course (92).

An elegant study by Perlow et al. revealed that pregnant women requiring long term administration of oral steroids are at an increased risk of pre-term labor and delivery as well as to develop gestational diabetes (95). Moreover, steroid-dependent $(95,96)$ but also non-steroid medicated (95) asthmatic mothers delivered more often low birth weight neonates with less than $2500 \mathrm{~g}$ than mothers without asthma. Intriguingly, the boost in asthma symptoms during pregnancy seems to correlate with the gender of the fetus. While women who delivered boys reported an improvement in their asthma during their pregnancy, mothers of girls, however, had increased asthma severity during gestation $(97,98)$. Women who were pregnant with a female fetus needed significantly more inhaled glucocorticoids in late pregnancy. For this particular group, it is proposed that an upregulation of inflammation is associated with asthma as gestation progressed (98). The mechanism behind is not entirely understood. In asthmatic mothers pregnant with female fetuses, the placental activity of the enzyme 11-hydroxysteroid dehydrogenase type 2 (11-HSD2) that metabolizes cortisol to inactive cortisone is reduced (98). This would increase the intracellular cortisol concentration in relation to variations in cytokine production in female placentas compared to male placenta explants (99). It was reported that the inflammatory response of placental trophoblast cells from male pregnancies after LPS stimulation is boosted probably because of the enhanced toll-like receptor (TLR)-4 expression in these cells (100). These fetal gender-specific differences should be taken into account during pregnancy in asthmatic women.

\section{PSORIASIS AND PREGNANCY}

About 25 million people in Europe and North America are affected by psoriasis that counts to the most prevalent immunemediated skin disease in adults (101). Psoriasis is considered to be a genetically programed, organ-specific (skin, or skin and joints) inflammatory disease (102) characterized by red, scaly, and raised plaques (101). Vascular dilation, bridged fenestrations, and gaps in endothelium, edematous areas in the cytoplasm of endotheliocytes, myocytes, and pericytes, basement membrane zone thickening and cell extravasation are reported as microvascular changes that occur in psoriatic lesions and represent signs of increased vascular permeability (103). Compared to asthma, psoriasis is considered to be a Th1-driven disease characterized by the infiltration of several T cell subsets, neutrophils, dendritic cells, natural killer T cells, and MCs $(102,104)$. All of them contribute to the inflammatory microenvironment that is composed of increased levels of interferon (IFN) $-\gamma$, tumor necrosis factor (TNF)- $\alpha$, IL-2, and IL12 (105) as well as IL-23 and IL-17A. MCs have been demonstrated to be key modulators of T-cell mediated responses and essentially involved in neutrophil recruitment (106). Recently, the important role of IL-17 producing Th17 cells in the pathogenesis of psoriasis has been reported (107). Neutrophils and MCs are other significant potential sources of IL-17A in psoriasis (108). In the superficial dermis of psoriatic skin, MC density is increased (104). It has been shown that alterations in psoriatic tissue appear to be initiated by degranulating MCs (109) and MC degranulation is among the earliest events in relapsing psoriasis lesions (109). Degranulated MCs have been found in close proximity to blood vessels in the area of psoriatic lesions (103). One can speculate that the survival of MCs in the tissue is regulated by their most important growth factor, the SCF that is intensely expressed in psoriatic tissue while its receptor KIT is upregulated in the surface of MCs (110).

Mast cells are typically classified into either $\mathrm{MC}_{\mathrm{T}}$ that contain only tryptase or $\mathrm{MC}_{\mathrm{TC}}$ that contain both proteases tryptase and chymase. Both subtypes in human are suggested to be equivalent to the murine $\mathrm{MC}$ phenotypes. While $\mathrm{MC}_{\mathrm{T}}$ seem to be related to immunological processes, $\mathrm{MC}_{\mathrm{TC}}$ appear to be linked to non-immunological responses including tissue remodeling and angiogenesis. The tryptase is the quantitatively dominant protease present in all MC phenotypes (111). In psoriatic skin, tryptasepositive cells are increased in number $(112,113)$. However, the determination of serum tryptase levels is not an appropriate tool to assess the severity of psoriasis as no correlation could be found between serum tryptase and psoriasis severity in patients (114). Tryptase levels in normal subjects are undetectable $(<1 \mathrm{ng} / \mathrm{ml})$ whereas in systemic MC disorders such as mastocytosis and anaphylaxis elevated tryptase levels can be detected (41).

It was reported that approximately $50 \%$ of patients develop psoriasis before the age of 25 (115). There are several studies showing that the natural course of psoriasis in women is modulated by menstrual cycle, pregnancy, and menopause $(5,115,116)$. All of these events during the reproductive cycle are under hormonal regulation. During pregnancy, more than $50 \%$ of the women reported an improvement of psoriasis at ca. the 30th week of pregnancy (midpregnancy) while more than $20 \%$ observed a worsening (116). At this time point, the shift from Th2 to Th1 immunity occurs mainly mediated by increased levels of estrogen, progesterone, and cortisol (90). It is assumed that during pregnancy and when hormone levels are increased, psoriatic symptoms improve. During puberty, post-partum and menopause when hormone levels decrease the disease severity seems to peak (117). Several Th1characterized diseases including psoriasis (116), multiple sclerosis (118), and rheumatoid arthritis $(119,120)$ have been shown to improve during pregnancy. Psoriatic body surface areas (BSA) decreased significantly from 10 to 20 weeks' gestation. Thereby, increased levels of estrogen relative to progesterone correlate with 
the improvement of psoriasis while progesterone concentrations alone did not correlate with changes in psoriatic symptoms. Interestingly, post-partum more than $60 \%$ of the patients reported worsening of symptoms while only $8.7 \%$ observed an improvement. But the authors found out that the "post-partum flare" was a return to the patients' baseline, rather than a real worsening (116).

It was reported that pregnant psoriatic women are at increased risk to adverse pregnancy outcomes including spontaneous and recurrent abortion, gestational hypertension, ectopic pregnancy, and pre-term rupture of membranes $(121,122)$. In fact, study results are controversial. Some showed an increased risk of adverse pregnancy outcomes, others did not. Psoriasis is definitely no contraindication for a pregnancy but a well-controlled disease and the monitoring of comorbidities, such metabolic syndrome, during pregnancy is of advantage. In contrast, generalized pustular psoriasis of pregnancy (GPPP), a special subtype of psoriasis occurring during pregnancy might be harmful for mother and child (123). In such cases, women should be kept on medical care by dermatologists. Several medications are available whose suitability and unsuitability for the treatment of psoriasis during pregnancy are reviewed by Lam et al. (124). However, safety data are limited because most of the data are based on case reports, which lack the comparison group of untreated patients (124). Women who need a disease-specific treatment should keep in mind that leaving a disease untreated during pregnancy may carry a greater risk to both the mother and fetus than any teratogenic risk of the drug to the fetus (124). Systemic treatment should be avoided when possible, but if necessary the best treatment option should be chosen on a case to case basis for optimized treatment during pregnancy.

\section{RESUME}

In general, there is no contraindication to pregnancy when MCrelated pathologies are under appropriate medical control. Women who were diagnosed with MC mediated or associated disorders and especially those whose disease is active, should be carefully advised by medical specialists to avoid severe pregnancy complications and to monitor disease progression. The unique modifications of the maternal endocrine and immune system can influence the number and behavior of MCs. Further studies addressing the molecular mechanisms behind the impact of pregnancy on MC mediated and associated disorders are needed in order to optimize pregnancy course and outcome.

\section{ACKNOWLEDGMENTS}

The authors wish to thank the strategic funding of the DFG priority programme 1394: Mast cells - promoters of health and modulators of disease and the COST Action BM1007: Mast cells and basophils-targets for innovative therapies.

\section{REFERENCES}

1. Woidacki K, Popovic M, Metz M, Schumacher A, Linzke N, Teles A, et al. Mast cells rescue implantation defects caused by c-kit deficiency. Cell Death Dis (2013) 4(1):e462. doi:10.1038/cddis.2012.214

2. Gibbs CJ, Coutts II, Lock R, Finnegan OC, White RJ. Premenstrual exacerbation of asthma. Thorax (1984) 39(11):833-6. doi:10.1136/thx.39.11.833

3. Beynon HL, Garbett ND, Barnes PJ. Severe premenstrual exacerbations of asthma: effect of intramuscular progesterone. Lancet (1988) 2(8607):370-2. doi:10.1016/S0140-6736(88)92837-1
4. Kemmett D. Premenstrual exacerbation of atopic dermatitis. Br J Dermatol (1989) 120(5):715. doi:10.1111/j.1365-2133.1989.tb01362.x

5. Kanda N, Watanabe S. Regulatory roles of sex hormones in cutaneous biology and immunology. J Dermatol Sci (2005) 38(1):1-7. doi:10.1016/j. jdermsci.2004.10.011

6. Sivridis E, Giatromanolaki A, Agnantis N, Anastasiadis P. Mast cell distribution and density in the normal uterus - metachromatic staining using lectins. Eur JObstet Gynecol Reprod Biol (2001) 98(1):109-13. doi:10.1016/S0301-2115(00) 00564-9

7. Galli SJ, Nakae S, Tsai M. Mast cells in the development of adaptive immune responses. Nat Immunol (2005) 6(2):135-42. doi:10.1038/ni1158

8. Hampton AL, Salamonsen LA. Expression of messenger ribonucleic acid encoding matrix metalloproteinases and their tissue inhibitors is related to menstruation. J Endocrinol (1994) 141(1):R1-3. doi:10.1677/joe.0. 141R001

9. Szukiewicz D, Szukiewicz A, Maslinska D, Gujski M, Poppe P, MazurekKantor J. Mast cell number, histamine concentration and placental vascular response to histamine in preeclampsia. Inflamm Res (1999) 48(Suppl 1):S39-40. doi:10.1007/s000110050390

10. Szewczyk G, Pyzlak M, Smiertka W, Klimkiewicz J, Szukiewicz D. Histamine stimulates alphav-beta3 integrin expression of the human trophoblast through the H(1) receptor. Inflamm Res (2006) 55(Suppl):1. doi:10.1007/s00011-0050052-y

11. Garfield RE, Irani A-M, Schwartz LB, Bytautiene E, Romero R. Structural and functional comparison of mast cells in the pregnant versus nonpregnant human uterus. Am J Obstet Gynecol (2006) 194(1):261-7. doi:10.1016/j. ajog.2005.05.011

12. Bytautiene E, Vedernikov YP, Saade GR, Romero R, Garfield RE. IgEindependent mast cell activation augments contractility of nonpregnant and pregnant guinea pig myometrium. Int Arch Allergy Immunol (2008) 147(2):140-6. doi:10.1159/000135701

13. Menzies FM, Shepherd MC, Nibbs RJ, Nelson SM. The role of mast cells and their mediators in reproduction, pregnancy and labour. Hum Reprod Update (2011) 17(3):383-96. doi:10.1093/humupd/dmq053

14. Saito H. Role of mast cell proteases in tissue remodeling. Chem Immunol Allergy (2005) 87:80-4. doi:10.1159/000087572

15. Romero R, Kusanovic JP, Muñoz H, Gomez R, Lamont RF, Yeo L. Allergyinduced preterm labor after the ingestion of shellfish. J Matern Fetal Neonatal Med (2010) 23(4):351-9. doi:10.3109/14767050903177193

16. Schwarz EB, Moretti ME, Nayak S, Koren G. Risk of hypospadias in offspring of women using loratadine during pregnancy: a systematic review and metaanalysis. Drug Saf (2008) 31(9):775-88. doi:10.2165/00002018-20083109000006

17. Zuberbier T, Asero R, Bindslev-Jensen C, Walter Canonica G, Church MK, Giménez-Arnau AM, et al. EAACI/GA(2)LEN/EDF/WAO guideline: management of urticaria. Allergy (2009) 64(10):1427-43. doi:10.1111/j.13989995.2009.02178.x

18. Kaplan AP, Greaves M. Pathogenesis of chronic urticaria. Clin Exp Allergy (2009) 39(6):777-87. doi:10.1111/j.1365-2222.2009.03256.x

19. Kasperska-Zajac A, Brzoza Z, Rogala B. Sex hormones and urticaria. J Dermatol Sci (2008) 52(2):79-86. doi:10.1016/j.jdermsci.2008.04.002

20. Schatz M, Zeiger RS. Asthma and allergy in pregnancy. Clin Perinatol (1997) 24(2):407-32.

21. Kasperska-Zajac A, Brzoza Z, Rogala B. Lower serum concentration of dehydroepiandrosterone sulphate in patients suffering from chronic idiopathic urticaria. Allergy (2006) 61(12):1489-90. doi:10.1111/j.1398-9995. 2006.01185.x

22. Brzoza Z, Kasperska-Zajac A, Oles E, Rogala B. Pruritic urticarial papules and plaques of pregnancy. J Midwifery Womens Health (2007) 52(1):44-8. doi:10.1016/j.jmwh.2006.09.007

23. Kröpfl L, Maurer M, Zuberbier T. Treatment strategies in urticaria. Expert Opin Pharmacother (2010) 11(9):1445-50. doi:10.1517/14656561003727500

24. Black MM. Polymorphic eruption of pregnancy. 2nd ed. In: Black MM editor. Obstetric and Gynecologic Dermatology. London: Mosby (2002). p. 39-44.

25. Rudolph CM, Al-Fares S, Vaughan-Jones SA, Mullegger RR, Kerl H, Black MM. Polymorphic eruption of pregnancy: clinicopathology and potential trigger factors in 181 patients. Br J Dermatol (2006) 154(1):54-60. doi:10.1111/j.13652133.2005.06856.x

26. Aronson IK, Bond S, Fiedler VC, Vomvouras S, Gruber D, Ruiz C. Pruritic urticarial papules and plaques of pregnancy: clinical and immunopathologic 
observations in 57 patients. J Am Acad Dermatol (1998) 39(6):933-9. doi:10. 1016/S0190-9622(98)70265-8

27. Vaughan Jones SA, Hern S, Nelson-Piercy C, Seed PT, Black MM. A prospective study of 200 women with dermatoses of pregnancy correlating clinical findings with hormonal and immunopathological profiles. Br J Dermatol (1999) 141(1):71-81. doi:10.1046/j.1365-2133.1999.02923.x

28. Kroumpouzos G, Cohen LM. Specific dermatoses of pregnancy: an evidencebased systematic review. Am J Obstet Gynecol (2003) 188(4):1083-92. doi:10. 1067/mob.2003.129

29. Carli P, Tarocchi S, Mello G, Fabbri P. Skin immune system activation in pruritic urticarial papules and plaques of pregnancy. Int J Dermatol (1994) 33(12):884-5.

30. Powell FC, Dervan P, Wayte J, O’Loughlin S. Pruritic urticarial papules and plaques of pregnancy (PUPPP): a clinicopathological review of 35 patients. $J$ Eur Acad Dermatol Venerol (1996) 6(2):105-11. doi:10.1111/j.1468-3083.1996. tb00153.x

31. Maddox DE, Reed CE. Clinical pharmacodynamics of antihistamines. Ann Allergy (1987) 59(6 Pt 2):43-8.

32. Staubach P, Onnen K, Vonend A, Metz M, Siebenhaar F, Tschentscher I, et al. Autologous whole blood injections to patients with chronic urticaria and a positive autologous serum skin test: a placebo-controlled trial. Dermatology (Basel) (2006) 212(2):150-9. doi:10.1159/000090656

33. Jeon IK, On HR, Oh SH, Hann SK. Three cases of pruritic urticarial papules and plaques of pregnancy (PUPPP) treated with intramuscular injection of autologous whole blood. J Eur Acad Dermatol Venereol (2014). doi:10.1111/ jdv. 12414

34. Metcalfe DD. Mast cells and mastocytosis. Blood (2008) 112(4):946-56. doi:10.1182/blood-2007-11-078097

35. van Doormaal, JJ, Arends S, Brunekreeft KL, van der Wal VB, Sietsma J, van Voorst Vader PC, et al. Prevalence of indolent systemic mastocytosis in a Dutch region. J Allergy Clin Immunol (2013) 131(5):1429-31. doi:10.1016/j. jaci.2012.10.015

36. Kristensen T, Vestergaard H, Bindslev-Jensen C, Møller MB, Broesby-Olsen S. Sensitive KIT D816V mutation analysis of blood as a diagnostic test in mastocytosis. Am J Hematol (2014) 89(5):493-8. doi:10.1002/ajh.23672

37. Nagata H, Worobec AS, Oh CK, Chowdhury BA, Tannenbaum S, Suzuki Y, et al. Identification of a point mutation in the catalytic domain of the protooncogene c-kit in peripheral blood mononuclear cells of patients who have mastocytosis with an associated hematologic disorder. Proc Natl Acad Sci U S A (1995) 92(23):10560-4. doi:10.1073/pnas.92.23.10560

38. Taylor ML, Dastych J, Sehgal D, Sundstrom M, Nilsson G, Akin C, et al. The Kitactivating mutation D816V enhances stem cell factor - dependent chemotaxis. Blood (2001) 98(4):1195-9. doi:10.1182/blood.V98.4.1195

39. Akin C, Jaffe ES, Raffeld M, Kirshenbaum AS, Daley T, Noel P, et al. An immunohistochemical study of the bone marrow lesions of systemic mastocytosis: expression of stem cell factor by lesional mast cells. Am J Clin Pathol (2002) 118(2):242-7. doi:10.1309/71KH-4JE4-E0J1-7THH

40. Hartmann K, Hermes B, Rappersberger K, Sepp N, Mekori YA, Henz BM. Evidence for altered mast cell proliferation and apoptosis in cutaneous mastocytosis. Br J Dermatol (2003) 149(3):554-9. doi:10.1046/j.1365-2133. 2003.05598.x

41. Schwartz LB. Tryptase from human mast cells: biochemistry, biology and clinical utility. Monogr Allergy (1990) 27:90-113.

42. Escribano L, Orfao A, Díaz-Agustin B, Villarrubia J, Cerveró C, López A, et al. Indolent systemic mast cell disease in adults: immunophenotypic characterization of bone marrow mast cells and its diagnostic implications. Blood (1998) 91(8):2731-6.

43. Escribano L, Díaz-Agustín B, Bellas C, Navalón R, Nuñez R, Sperr WR, et al. Utility of flow cytometric analysis of mast cells in the diagnosis and classification of adult mastocytosis. Leuk Res (2001) 25(7):563-70. doi:10.1016/S01452126(01)00050-9

44. Taylor ML, Sehgal D, Raffeld M, Obiakor H, Akin C, Mage RG, et al. Demonstration that mast cells, $\mathrm{T}$ cells, and $\mathrm{B}$ cells bearing the activating kit mutation D816V occur in clusters within the marrow of patients with mastocytosis. J Mol Diagn (2004) 6(4):335-42. doi:10.1016/S15251578(10)60529-6

45. Worobec AS, Akin C, Scott LM, Metcalfe DD. Mastocytosis complicating pregnancy. Obstet Gynecol (2000) 95(3):391-5. doi:10.1016/S0029-7844(99) 00591-8
46. Matito A, Álvarez-Twose I, Morgado JM, Sánchez-Muñoz L, Orfao A, Escribano L. Clinical impact of pregnancy in mastocytosis: a study of the Spanish Network on Mastocytosis (REMA) in 45 cases. Int Arch Allergy Immunol (2011) 156(1):104-11. doi:10.1159/000321954

47. Abrahams VM, Kim YM, Straszewski SL, Romero R, Mor G. Macrophages and apoptotic cell clearance during pregnancy. Am J Reprod Immunol (2004) 51(4):275-82. doi:10.1111/j.1600-0897.2004.00156.x

48. Koga K, Mor G. Toll-like receptors at the maternal-fetal interface in normal pregnancy and pregnancy disorders. Am J Reprod Immunol (2010) 63(6):587-600. doi:10.1111/j.1600-0897.2010.00848.x

49. Mor G, Cardenas I, Abrahams V, Guller S. Inflammation and pregnancy: the role of the immune system at the implantation site. Ann N Y Acad Sci (2011) 1221(1):80-7. doi:10.1111/j.1749-6632.2010.05938.x

50. Watson KD, Arendt KW, Watson WJ, Volcheck GW. Systemic Mastocytosis Complicating Pregnancy. Obstetr Gynecol (2012) 119(2 Pt 2):486-9. doi:10.1097/AOG.0b013e318242d3c5

51. Ulbrich F, Engelstädter H, Wittau N, Steinmann D. Anaesthetic management of emergency caesarean section in a parturient with systemic mastocytosis. Int J Obstet Anesth (2013) 22(3):243-6. doi:10.1016/j.ijoa.2013.03.011

52. Soter NA. Morphology of atopic eczema. Allergy (1989) 44(Suppl 9):16-9. doi:10.1111/j.1398-9995.1989.tb04310.x

53. Sugiura H, Maeda T, Uehara M. Mast cell invasion of peripheral nerve in skin lesions of atopic dermatitis. Acta Derm Venereol Suppl (Stockh) (1992) 176:74-6.

54. Katayama I, Yokozeki H, Nishioka K. Mast-cell-derived mediators induce epidermal cell proliferation: clue for lichenified skin lesion formation in atopic dermatitis. Int Arch Allergy Immunol (1992) 98(4):410-4. doi:10.1159/ 000236218

55. Ingber A. Atopic eruption of pregnancy. J Eur Acad Dermatol Venereol (2010) 24(8):984. doi:10.1111/j.1468-3083.2010.03690.x

56. Koutroulis I, Papoutsis J, Kroumpouzos G. Atopic dermatitis in pregnancy: current status and challenges. Obstet Gynecol Surv (2011) 66(10):654-63. doi:10.1097/OGX.0b013e31823a0908

57. Kemmett D, Tidman MJ. The influence of the menstrual cycle and pregnancy on atopic dermatitis. Br J Dermatol (1991) 125(1):59-61. doi:10.1111/j.13652133.1991.tb06041.x

58. Cho S, Kim HJ, Oh SH, Park CO, Jung JY, Lee KH. The influence of pregnancy and menstruation on the deterioration of atopic dermatitis symptoms. Ann Dermatol (2010) 22(2):180-5. doi:10.5021/ad.2010.22.2.180

59. Akdis M, Trautmann A, Blaser K, Akdis CA. T cells and effector mechanisms in the pathogenesis of atopic dermatitis. Curr Allergy Asthma Rep (2002) 2(1):1-3. doi:10.1007/s11882-002-0029-7

60. Horsmanheimo L, Harvima IT, Järvikallio A, Harvima RJ, Naukkarinen A, Horsmanheimo M. Mast cells are one major source of interleukin-4 in atopic dermatitis. Br J Dermatol (1994) 131(3):348-53. doi:10.1111/j.1365-2133. 1994.tb08522.x

61. Maggi E, Parronchi P, Manetti R, Simonelli C, Piccinni MP, Rugiu FS, et al. Reciprocal regulatory effects of IFN-gamma and IL-4 on the in vitro development of human Th1 and Th2 clones. J Immunol (1992) 148(7):2142-7.

62. Monroe JG, Haldar S, Prystowsky MB, Lammie P. Lymphokine regulation of inflammatory processes: interleukin-4 stimulates fibroblast proliferation. Clin Immunol Immunopathol (1988) 49(2):292-8. doi:10.1016/0090-1229(88) 90119-5

63. Berroth A, Kühnl J, Kurschat N, Schwarz A, Stäb F, Schwarz T, et al. Role of fibroblasts in the pathogenesis of atopic dermatitis. J Allergy Clin Immunol (2013) 131(6):1547-54. doi:10.1016/j.jaci.2013.02.029

64. Chen W, Mempel M, Schober W, Behrendt H, Ring J. Gender difference, sex hormones, and immediate type hypersensitivity reactions. Allergy (2008) 63(11):1418-27. doi:10.1111/j.1398-9995.2008.01880.x

65. Weatherhead S, Robson SC, Reynolds NJ. Eczema in pregnancy. BMJ (2007) 335(7611):152-4. doi:10.1136/bmj.39227.671227.AE

66. Babalola O, Strober BE. Treatment of atopic dermatitis in pregnancy. Dermatol Ther (2013) 26(4):293-301. doi:10.1111/dth.12074

67. Katz VL, Thorp JM, Bowes WA. Severe symmetric intrauterine growth retardation associated with the topical use of triamcinolone. Am J Obstet Gynecol (1990) 162(2). 396-7. doi:10.1016/0002-9378(90)90394-M

68. Masoli M, Fabian D, Holt S, Beasley R. The global burden of asthma: executive summary of the GINA Dissemination Committee report. Allergy (2004) 59(5):469-78. doi:10.1111/j.1398-9995.2004.00526.x 
69. Narita S-I, Goldblum RM, Watson CS, Brooks EG, Estes DM, Curran EM, et al. Environmental estrogens induce mast cell degranulation and enhance IgE-mediated release of allergic mediators. Environ Health Perspect (2007) 115(1):48-52. doi:10.1289/ehp.9378

70. Martinez FD, Vercelli D. Asthma. Lancet (2013) 382(9901):1360-72. doi:10. 1016/S0140-6736(13)61536-6

71. Marketos SG, Ballas CN. Bronchial asthma in the medical literature of Greek antiquity. J Asthma (1982) 19(4):263-9. doi:10.3109/02770908209104771

72. King GG, Paré PD, Seow CY. The mechanics of exaggerated airway narrowing in asthma: the role of smooth muscle. Respir Physiol (1999) 118(1):1-13. doi:10.1016/S0034-5687(99)00076-6

73. Lambrecht BN, Hammad H. The airway epithelium in asthma. Nat Med (2012) 18(5):684-92. doi:10.1038/nm.2737

74. Foresi A, Bertorelli G, Pesci A, Chetta A, Olivieri D. Inflammatory markers in bronchoalveolar lavage and in bronchial biopsy in asthma during remission. Chest (1990) 98(3):528-35. doi:10.1378/chest.98.3.528

75. Bradding P, Roberts JA, Britten KM, Montefort S, Djukanovic R, Mueller R, et al. Interleukin-4, -5 , and -6 and tumor necrosis factor-alpha in normal and asthmatic airways: evidence for the human mast cell as a source of these cytokines. Am J Respir Cell Mol Biol (1994) 10(5):471-80. doi:10.1165/ajrcmb. 10.5.8179909

76. Brightling CE, Bradding P, Symon FA, Holgate ST, Wardlaw AJ, Pavord ID. Mast-cell infiltration of airway smooth muscle in asthma. N Engl J Med (2002) 346(22):1699-705. doi:10.1056/NEJMoa012705

77. Carroll NG, Mutavdzic S, James AL. Distribution and degranulation of airway mast cells in normal and asthmatic subjects. Eur Respir J (2002) 19(5):879-85. doi:10.1183/09031936.02.00275802

78. Berger P, Girodet P-O, Begueret H, Ousova O, Perng D-W, Marthan R, et al. Tryptase-stimulated human airway smooth muscle cells induce cytokine synthesis and mast cell chemotaxis. FASEB J (2003) 17(14):2139-41. doi:10.1096/ fj.03-0041fje

79. Brightling CE, Ammit AJ, Kaur D, Black JL, Wardlaw AJ, Hughes JM, et al. The CXCL10/CXCR3 axis mediates human lung mast cell migration to asthmatic airway smooth muscle. Am J Respir Crit Care Med (2005) 171(10):1103-8. doi:10.1164/rccm.200409-1220OC

80. Bradding P, Walls AF, Holgate ST. The role of the mast cell in the pathophysiology of asthma. J Allergy Clin Immunol (2006) 117(6):1277-84. doi:10.1016/ j.jaci.2006.02.039

81. Hollins F, Kaur D, Yang W, Cruse G, Saunders R, Sutcliffe A, et al. Human airway smooth muscle promotes human lung mast cell survival, proliferation, and constitutive activation: cooperative roles for CADM1, stem cell factor, and IL-6. J Immunol (2008) 181(4):2772-80. doi:10.4049/jimmunol. 181.4.2772

82. Moiseeva EP, Roach KM, Leyland ML, Bradding P. CADM1 is a key receptor mediating human mast cell adhesion to human lung fibroblasts and airway smooth muscle cells. PLoS One (2013) 8(4):e61579. doi:10.1371/journal.pone. 0061579

83. Bradding P. Mast cells in asthma. 2. ed. In: Busse WW editor. Asthma and Rhinitis. Oxford: Blackwell Science (2000). p. 319-38.

84. Barsky HE. Asthma and pregnancy. A challenge for everyone concerned. Postgrad Med (1991) 89(1):125-30.

85. Deckers J, Branco Madeira F, Hammad H. Innate immune cells in asthma. Trends Immunol (2013) 34(11):540-7. doi:10.1016/j.it.2013.08.004

86. O’Leary P, Boyne P, Flett P, Beilby J, James I. Longitudinal assessment of changes in reproductive hormones during normal pregnancy. Clin Chem (1991) 37(5):667-72.

87. Bouman A, Heineman MJ, Faas MM. Sex hormones and the immune response in humans. Hum Reprod Update (2005) 11(4):411-23. doi:10.1093/humupd/ dmi008

88. Siracusa MC, Overstreet MG, Housseau F, Scott AL, Klein SL. 17beta-estradiol alters the activity of conventional and IFN-producing killer dendritic cells. J Immunol (2008) 180(3). 1423-31. doi:10.4049/jimmunol.180.3.1423

89. Roby KF, Hunt JS. Myometrial tumor necrosis factor alpha: cellular localization and regulation by estradiol and progesterone in the mouse. Biol Reprod (1995) 52(3):509-15. doi:10.1095/biolreprod52.3.509

90. Piccinni M, Scaletti C, Maggi E, Romagnani S. Role of hormone-controlled Th1- and Th2-type cytokines in successful pregnancy. J Neuroimmunol (2000) 109(1):30-3. doi:10.1016/S0165-5728(00)00299-X
91. Ostensen M, Brucato A, Carp H, Chambers C, Dolhain RJEM, Doria A, et al. Pregnancy and reproduction in autoimmune rheumatic diseases. Rheumatology (2011) 50(4):657-64. doi:10.1093/rheumatology/keq350

92. Schatz M, Harden K, Forsythe A, Chilingar L, Hoffman C, Sperling W, et al. The course of asthma during pregnancy, post partum, and with successive pregnancies: a prospective analysis. J Allergy Clin Immunol (1988) 81(3):509-17. doi:10.1016/0091-6749(88)90187-X

93. Zhao XJ, McKerr G, Dong Z, Higgins CA, Carson J, Yang ZQ, et al. Expression of oestrogen and progesterone receptors by mast cells alone, but not lymphocytes, macrophages or other immune cells in human upper airways. Thorax (2001) 56(3):205-11. doi:10.1136/thorax.56.3.205

94. Jensen F, Woudwyk M, Teles A, Woidacki K, Taran F, Costa S, et al. Estradiol and progesterone regulate the migration of mast cells from the periphery to the uterus and induce their maturation and degranulation. PLoS One (2010) 5(12):e14409. doi:10.1371/journal.pone.0014409

95. Perlow JH, Montgomery D, Morgan MA, Towers CV, Porto M. Severity of asthma and perinatal outcome. Am J Obstet Gynecol (1992) 167(4 Pt 1):963-7. doi:10.1016/S0002-9378(12)80020-2

96. Schatz M, Dombrowski MP, Wise R, Momirova V, Landon M, Mabie W, et al. The relationship of asthma medication use to perinatal outcomes. J Allergy Clin Immunol (2004) 113(6):1040-5. doi:10.1016/j.jaci.2004.03.017

97. Dodds L, Armson BA, Alexander S. Use of asthma drugs is less among women pregnant with boys rather than girls. BMJ (1999) 318(7189):1011. doi:10.1136/bmj.318.7189.1011

98. Murphy VE, Gibson PG, Giles WB, Zakar T, Smith R, Bisits AM, et al. Maternal asthma is associated with reduced female fetal growth. Am J Respir Crit Care Med (2003) 168(11):1317-23. doi:10.1164/rccm.200303-374OC

99. Scott NM, Hodyl NA, Osei-Kumah A, Stark MJ, Smith R, Clifton VL. The presence of maternal asthma during pregnancy suppresses the placental proinflammatory response to an immune challenge in vitro. Placenta (2011) 32(6):454-61. doi:10.1016/j.placenta.2011.03.004

100. Yeganegi M, Watson CS, Martins A, Kim SO, Reid G, Challis JR, et al. Effect of Lactobacillus rhamnosus GR-1 supernatant and fetal sex on lipopolysaccharide-induced cytokine and prostaglandin-regulating enzymes in human placental trophoblast cells: implications for treatment of bacterial vaginosis and prevention of preterm labor. Am J Obstet Gynecol (2009) 200(5):532.e1-8. doi:10.1016/j.ajog.2008.12.032

101. Lowes MA, Bowcock AM, Krueger JG. Pathogenesis and therapy of psoriasis. Nature (2007) 445(7130):866-73. doi:10.1038/nature05663

102. Gaspari AA. Innate and adaptive immunity and the pathophysiology of psoriasis. J Am Acad Dermatol (2006) 54(3):S67-80. doi:10.1016/j.jaad.2005. 10.057

103. Mordovtsev VN, Albanova VI. Morphology of skin microvasculature in psoriasis. Am J Dermatopathol (1989) 11(1):33-42. doi:10.1097/00000372198902000-00006

104. Töyry S, Fräki J, Tammi R. Mast cell density in psoriatic skin. The effect of PUVA and corticosteroid therapy. Arch Dermatol Res (1988) 280(5):282-5. doi:10.1007/BF00440601

105. Schlaak JF, Buslau M, Jochum W, Hermann E, Girndt M, Gallati H, et al. T cells involved in psoriasis vulgaris belong to the Th1 subset. J Invest Dermatol (1994) 102(2):145-9. doi:10.1111/1523-1747.ep12371752

106. Biedermann T, Kneilling M, Mailhammer R, Maier K, Sander CA, Kollias $\mathrm{G}$, et al. Mast cells control neutrophil recruitment during $\mathrm{T}$ cell-mediated delayed-type hypersensitivity reactions through tumor necrosis factor and macrophage inflammatory protein 2. J Exp Med (2000) 192(10):1441-52. doi:10.1084/jem.192.10.1441

107. Lynde CW, Poulin Y, Vender R, Bourcier M, Khalil S. Interleukin 17A: toward a new understanding of psoriasis pathogenesis. J Am Acad Dermatol (2014) doi:10.1016/j.jaad.2013.12.036

108. Lin AM, Rubin CJ, Khandpur R, Wang JY, Riblett M, Yalavarthi S, et al. Mast cells and neutrophils release IL-17 through extracellular trap formation in psoriasis. J Immunol (2011) 187(1):490-500. doi:10.4049/jimmunol.1100123

109. Schubert C, Christophers E. Mast cells and macrophages in early relapsing psoriasis. Arch Dermatol Res (1985) 277(5):352-8. doi:10.1007/BF00509232

110. Huttunen M, Naukkarinen A, Horsmanheimo M, Harvima IT. Transient production of stem cell factor in dermal cells but increasing expression of Kit receptor in mast cells during normal wound healing. Arch Dermatol Res (2002) 294(7):324-30. doi:10.1007/s00403-002-0331-1 
111. Church MK, Levi-Schaffer F. The human mast cell. J Allergy Clin Immunol (1997) 99(2):155-60. doi:10.1016/S0091-6749(97)70089-7

112. Harvima IT, Naukkarinen A, Paukkonen K, Harvima RJ, Aalto ML, Schwartz LB, et al. Mast cell tryptase and chymase in developing and mature psoriatic lesions. Arch Dermatol Res (1993) 285(4):184-92. doi:10.1007/ BF00372007

113. Harvima IT, Nilsson G, Suttle M-M, Naukkarinen A. Is there a role for mast cells in psoriasis? Arch Dermatol Res (2008) 300(9):461-78. doi:10.1007/ s00403-008-0874-x

114. Gerdes S, Kurrat W, Mrowietz U. Serum mast cell tryptase is not a useful marker for disease severity in psoriasis or atopic dermatitis. $\mathrm{Br} J$ Dermatol (2009) 160(4):736-40. doi:10.1111/j.1365-2133.2008.08972.x

115. Swanbeck G, Inerot A, Martinsson T, Wahlström J. A population genetic study of psoriasis. Br J Dermatol (1994) 131(1):32-9. doi:10.1111/j.1365-2133.1994. tb08454.x

116. Murase JE, Chan KK, Garite TJ, Cooper DM, Weinstein GD. Hormonal effect on psoriasis in pregnancy and post partum. Arch Dermatol (2005) 141(5):601-6. doi:10.1001/archderm.141.5.601

117. Ceovic R, Mance M, Bukvic Mokos Z, Svetec M, Kostovic K, Stulhofer Buzina D. Psoriasis: female skin changes in various hormonal stages throughout life puberty, pregnancy, and menopause. Biomed Res Int (2013) 2013(1):571912. doi:10.1155/2013/571912

118. Confavreux C, Hutchinson M, Hours MM, Cortinovis-Tourniaire P, Moreau T. Rate of pregnancy-related relapse in multiple sclerosis. Pregnancy in Multiple Sclerosis Group. N Engl J Med (1998) 339(5):285-91. doi:10.1056/ NEJM199807303390501

119. Hench PS. The ameliorating effect of pregnancy on chronic atrophic (infectious rheumatoid) arthritis, fibrositis, and intermittent hydrarthrosis. Proc Mayo Clinic (1938) 13:161-6.

120. Nelson JL, Hughes KA, Smith AG, Nisperos BB, Branchaud AM, Hansen JA. Remission of rheumatoid arthritis during pregnancy and maternal-fetal class II alloantigen disparity. Am J Reprod Immunol (1992) 28(3-4):226-7. doi:10.1111/j.1600-0897.1992.tb00798.x

121. Ben-David G, Sheiner E, Hallak M, Levy A. Pregnancy outcome in women with psoriasis. J Reprod Med (2008) 53(3):183-7. doi:10.1016/j.ajog.2005.10.364

122. Cohen-Barak E, Nachum Z, Rozenman D, Ziv M. Pregnancy outcomes in women with moderate-to-severe psoriasis. J Eur Acad Dermatol Venereol (2011) 25(9):1041-7. doi:10.1111/j.1468-3083.2010.03917.x

123. Lehrhoff S, Pomeranz MK. Specific dermatoses of pregnancy and their treatment. Dermatol Ther (2013) 26(4):274-84. doi:10.1111/dth.12078

124. Lam J, Polifka JE, Dohil MA. Safety of dermatologic drugs used in pregnant patients with psoriasis and other inflammatory skin diseases. J Am Acad Dermatol (2008) 59(2):295-315. doi:10.1016/j.jaad.2008.03.018

Conflict of Interest Statement: The authors declare that the research was conducted in the absence of any commercial or financial relationships that could be construed as a potential conflict of interest.

Received: 28 March 2014; paper pending published: 22 April 2014; accepted: 05 May 2014; published online: 19 May 2014.

Citation: Woidacki K, Zenclussen AC and Siebenhaar F (2014) Mast cell-mediated and associated disorders in pregnancy: a risky game with an uncertain outcome? Front. Immunol. 5:231. doi: 10.3389/fimmu.2014.00231

This article was submitted to Inflammation, a section of the journal Frontiers in Immunology.

Copyright (c) 2014 Woidacki, Zenclussen and Siebenhaar. This is an open-access article distributed under the terms of the Creative Commons Attribution License (CC BY). The use, distribution or reproduction in other forums is permitted, provided the original author(s) or licensor are credited and that the original publication in this journal is cited, in accordance with accepted academic practice. No use, distribution or reproduction is permitted which does not comply with these terms. 